\title{
Enhancing Transportation Education through Online Simulation Using an Agent-Based Demand and Assignment Model
}

\author{
Shanjiang Zhu'; Feng Xie ${ }^{2}$; and David Levinson ${ }^{3}$
}

\begin{abstract}
This research explores the effectiveness of using simulation as a tool for enhancing classroom learning in the Civil Engineering Department of the University of Minnesota at Twin Cities. The authors developed a modern transportation planning software package, Agent-Based Demand and Assignment Model (ADAM), that is consistent with our present understanding of travel behavior, that is platform independent, and that is easy to learn and is thus usable by students. An in-class project incorporated ADAM and the performance of this education strategy was evaluated through preclass survey, postclass survey, scores in the quiz focusing on travel demand modeling, and final scores. Results showed that ADAM effectively enhanced students' self-reported understanding of transportation planning and their skills of forming opinions, evaluating projects, and making judgments. Students who prefer visual and active learning were found to benefit more than others through simulation-based teaching strategy. Findings in this research could have significant implications for future practice of simulation-based teaching strategy.
\end{abstract}

DOI: $10.1061 /(A S C E) E I .1943-5541.0000038$

CE Database subject headings: Transportation engineering; Engineering education; Simulation.

Author keywords: Agent-based model; Transportation education; Simulation.

\section{Introduction}

The practice of transportation engineering and planning has evolved substantially over the past several decades. Young graduates encounter a wide range of increasingly complicated problems, from growing congestion and worsening air quality, to environmental preservation and social equity concerns (Handy et al. 2002). The task of transportation education in this era, as stated by an ITE Technical Council Committee 2-32 (1990), is not only "to train students in how to do various activities associated with current practice" but also to "provide students with the tools necessary to solve new problems that arise." However, achieving this goal poses a significant challenge for transportation engineering educators given that the hourly requirement of transportation-related courses offered for undergraduate students is decreasing (Lipinski and Wilson 1992; Mason 2003).

Other factors that contribute to this challenge include the fact that most transportation-related courses are still addressed in a

${ }^{1}$ Ph.D. Student, Dept. of Civil Engineering, Univ. of Minnesota, 500 Pillsbury Dr., S.E., Minneapolis, MN 55455. E-mail: zhuxx120@ umn.edu

${ }^{2}$ Transportation Engineer at National Capital Region Transportation Planning Board, Metropolitan Washington Council of Governments, 777 North Capitol St., NE Suite 300, Washington, DC 20002. E-mail: fxie@wcog.org

${ }^{3}$ Associate Professor, Dept. of Civil Engineering, Univ. of Minnesota, 500 Pillsbury Dr., S.E., Minneapolis, MN 55455. E-mail: dlevinson@ umn.edu

Note. This manuscript was submitted on September 4, 2009; approved on April 5, 2010; published online on April 13, 2010. Discussion period open until June 1, 2011; separate discussions must be submitted for individual papers. This paper is part of the Journal of Professional Issues in Engineering Education and Practice, Vol. 137, No. 1, January 1, 2011. (C)ASCE, ISSN 1052-3928/2011/1-38-45/\$25.00. traditional instructional format with "chalk and talk" lectures, paper and pencil problem-solving, and class projects or papers on related topics (Mills and Treagust 2003; Chen and Levinson 2006), which fails to motivate students (e.g., Carlson and Sullivan 1999) and prevents these students from effectively applying what they learn in their future work. For instance, Hadgraft (1992) found that students receiving traditional lectures lack the skills to effectively define and recognize problems, which comprises their ability to apply learned knowledge to solve problems. As a consequence, a recent survey conducted by Mason (2003) indicates that the number of graduates in transportation engineering have decreased slightly, despite increasing demand from the industry. For these reasons, significant curriculum changes are needed that will better engage students and more effectively disseminate knowledge.

One of the more promising tools in this effort includes using computer-based simulation to enhance classroom instruction (Rafaeli et al. 2003; Stoffa and Slovakia 2004). This strategy, however, has not been widely adopted in the education of transportation engineering and planning, largely due to a twofold barrier. First, traditional theories and models may be difficult to embody in a simple and clear simulation suitable for class uses. Second, the effectiveness of simulation has seldom been examined in education practice, and thus its potential advantages over traditional ways of learning have not been widely acknowledged.

In this paper, an online simulator of travel demand modeling is developed based on recent advances in transportation planning models. Its effectiveness is evaluated based on surveys before and after the use of this simulator in a junior level transportation engineering class. This paper documents the process and report findings that help to demonstrate the suitability of simulation in the classroom. The next section presents a review of related educational theories on simulation. Then the Agent-Based Demand and Assignment Model (ADAM) simulator is introduced followed 
by a brief description of the project. The results section reports the evaluation results based on statistical analyses of surveyed data, while the conclusion summarizes our findings and gives implications of our study.

\section{Online Simulation in Education}

Advanced education and teaching are increasingly based on technological innovations in the area of multimedia and computerbased instruction (Alavi et al. 1997). Among the proposed techniques, computer simulation is particularly valuable in transportation education because most transportation policies and strategies in the real world take years to implement with a prohibitively high cost, while simulation allows learners to "apply new skills in a risk-free environment" (Billhardt 2004). Furthermore, simulation allows interactions between the computer program and students and provides prompt feedback to students, which has proven to be critical to good education (Chickering and Gamson 1987). A simulator with an interactive interface and graphical feedback could engage students in the subject matter and encourage students to concentrate, thereby increasing their learning, understanding, and retention. Provided with a simulator which models an entire system, students will be able to move beyond atomistic equations that, to date, have constituted the majority of instruction in the course, and look at transportation issues in a holistic way.

There are, of course, more advanced commercial transportation planning packages, such as EMME/3, TRANSCAD, TRANSIMS, and CUBE/TRANPLAN, but those have steep learning curves making them inappropriate for the classroom setting (Chen and Levinson 2006). The high price of commercial packages (despite educational discounts) further increases the difficulty for universities to adopt them in classroom. Other simpler packages exist (e.g., QRS-II), but these are still fairly complicated to learn and implement, based on traditional transportation planning models, and are not platform-independent. Prior to this project, the class used software called The Highway Emulator (T.H.E.) which, while relatively simple, did not have a graphical input or output and was DOS based.

The Internet provides a more attractive frontier for computer simulation in transportation education. Ubiquitous access to the Internet relaxes the time and location constraints of learning. Online simulators also enable easy delivery and fast customization (Rafaeli et al. 2003). Thus, many transportation researchers and educators have chosen online simulators to publish their work (Bolay and Helbing 2006; Treiber 2005; Los Alamos National Laboratory 1998).

\section{ADAM}

The traditional travel demand model adopted by many classic textbooks (Sheffi 1985; Banks 2002) considers aggregate travel choices in four steps: trip generation, traffic distribution, modal split, and traffic assignment. It was developed in the 1950s when data, computational power, and sophisticated algorithms were less readily available to professionals. The four-step model, therefore, suffers many weaknesses such as the inability to incorporate the diversity of travelers. The model lacks a solid foundation in travel behavior theory (Zhang and Levinson 2004). In our own classrooms, these deficiencies in the model tended to confuse students because the mathematical concepts underlying the model are dif- ficult to grasp. The concept of equilibrium introduced in traffic assignment is too abstract for undergraduates who have little background in transportation research or optimization and the gravity model is not an intuitive method for conceptualizing their daily travel needs. The four-step model also ignores the interactions between different steps and is sometimes misleading. For example, students are often confused by induced travel or demand (Parthasarathi et al. 2003), which can be thought of as a feedback from traffic assignment to trip generation, distribution, and mode split.

The agent-based travel demand model has emerged as a new generation of transportation forecasting tools and provides an alternative to address the topic of travel demand modeling. The agent-based modeling approach assumes that the aggregate urban travel demand is the result of a multidimensional choice process, including residential and business location choice, trip origin, trip destination, route choice, etc. All agents have individual characteristics, goals, and rules of travel behaviors. Agents exchange information on their experiences and adjust their travel choices according to available information. This modeling framework could be more intuitive for students because it simulates the decision-making process in travel at a microscopic level in a way that students may experience first-hand on a daily basis. Ideally, the modeling framework is flexible and is open for students to specify and test their assumption of travelers' goals and behavioral rules (i.e., how travelers value their time, how much travelers would like to pay for 10-min travel time saving), which will greatly enhance students' understanding of underlying mechanisms behind travel demand forecasting.

The online simulator named ADAM is developed to implement a simple agent-based travel demand model in a classroom setting. ADAM aims to be easy to learn, platform-independent, and consistent with the present understanding of transportation theories. The flowchart of ADAM is illustrated in Fig. 1 and more details of this model can be found in Zhang and Levinson (2004). For simplicity, this model focuses on the morning peak period and each traveler is treated as an autonomous agent who hunts for a job on the network. After all travelers have found their jobs, a travel pattern of the city is established and the aggregate measure of effectiveness (MOE), such as vehicle kilometers of travel (vkt), vehicle hours of travel (vht), and network accessibility, can be measured. As travelers adjust their destination and route choices, the travel pattern will evolve until convergence is reached.

A snapshot of the simulator interface is presented in Fig. 2. As can be seen, the interface is composed of three major panels. The aforementioned resulting patterns and MOEs can be examined after a simulation via the result panel. In the parameter panel, users are free to adjust model parameters such as travelers' willingness to travel, sensitivity to travel cost, and flow-speed relationship within specified ranges. In the display panel, the topology of the examined transportation network is displayed. For the default case, this simulator displays a simplified road network of the City of Sioux Falls, South Dakota (a standard test case in transportation research).

Different attributes of links and nodes, such as the number of lanes, speed, number of travelers originating from and destined for a node, are differentiated on the screen in different colors or sizes. Pop-up labels which can be seen by right-clicking provide an alternative way to obtain the information about a link or node, which provides students immediate feedback in their uses. Another feature of ADAM is that it allows onscreen editing on the examined network. Users are allowed to change the topology of a network and specify the attributes of links and nodes through the 


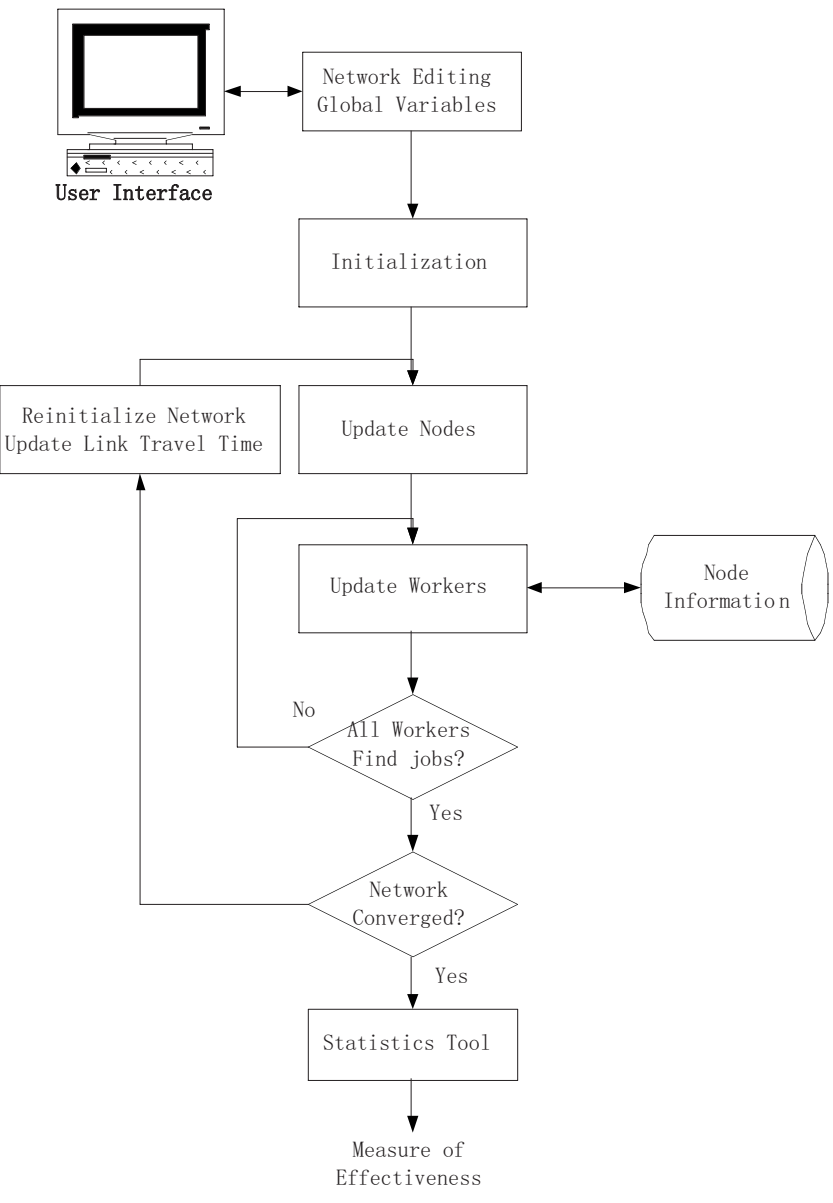

Fig. 1. Flow chart of ADAM screen. This function provides flexibility for classroom assignments in network design and urban planning, and thus encourages active and creative learning.

\section{Class Project}

Introduction to Transportation Engineering, CE3201, is a required Civil Engineering course at the University of Minnesota, Twin Cities, taught every semester to up to 75 students, usually taken by sophomores or juniors (though out-of-sequence seniors often take the course to complete requirements). Currently, students in CE3201 have a lecture that meets $2 \mathrm{~h}$ a week and a computer lab that meets $1 \mathrm{~h}$ a week. For the Transportation Planning portion of the course (approximately the first month), students in lab previously used software called T.H.E., which is a simplified version of a 1950s era transportation planning software package rewritten for personal computers and was developed in 1989.

ADAM was first introduced to CE3201 to replace T.H.E. so that travel demand forecasting can be learned in a classroom setting in less than 3 lab periods via a usable tool. Three project assignments are designed to incorporate the simulator into classroom learning, each for one class period. The first two assignments allow students to familiarize themselves with travel demand modeling and the simulator and the third asks each student to develop a redevelopment plan of the Sioux Falls network under given situations using ADAM and to evaluate the efficiency of that plan.

\section{Evaluation}

Two surveys were conducted before and after the class project to evaluate the effectiveness of ADAM. The preclass survey is de-

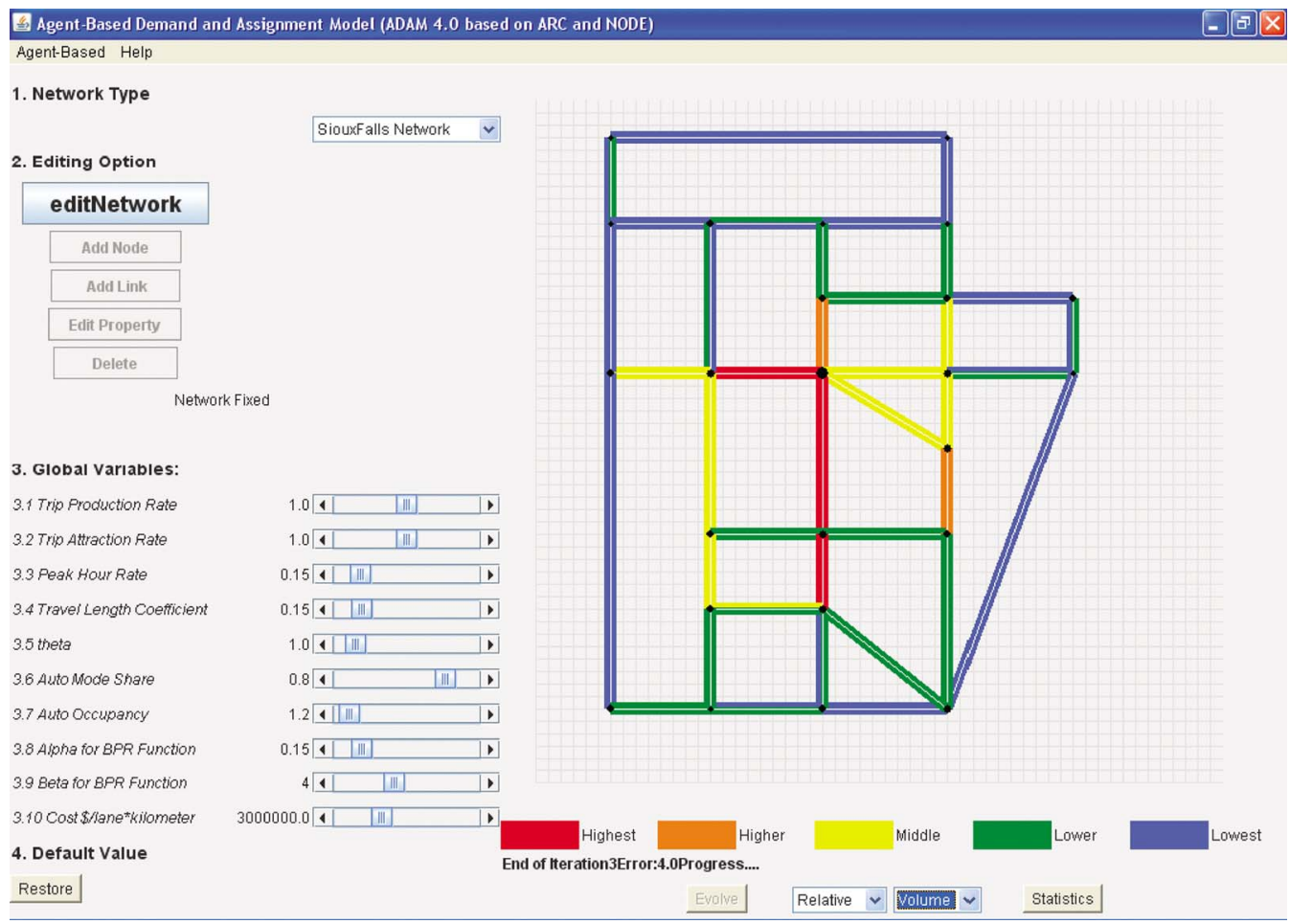

Fig. 2. User interface of ADAM 
Table 1. Evaluation Design

\begin{tabular}{lc}
\hline Evaluation objective & Survey questions \\
\hline Preclass survey & Demographic \\
Confounding factors & Academic background \\
Professional background \\
Computer proficiency \\
Learning style \\
Prior understanding of topics \\
Prior ability of identify relationship \\
Prior ability of forming opinions \\
Prior ability of judgment
\end{tabular}

Postclass survey

Learning outcomes

Subjective understanding of topics Ability of identify relationship Ability of forming opinions Ability of judgment

Efficacy assessment of $\mathrm{ADAM}$ as a learning tool

Quality of project

Time taken to finish the project Supporting materials proficiency Overall satisfaction

Quiz I

Final score

Understanding of travel demand modeling Overall academic performance

signed to collect students' background information, while the postclass survey is designed to assess students' self-reported improvement in knowledge and skills after using the simulator for a 3 -week period, and collect their evaluations of the simulator as a tool of learning. Table 1 summarizes the categories of questions adopted in both the preclass and postclass surveys. To be consistent with previous surveys, the questions on learning style are adopted from Kolb (1984) and Felder and Silverman (1988). In addition to the postclass survey, the grades of the first quiz, which specifically focuses on travel demand modeling, serve as an indicator of learning performance, while the final grades of the whole class are incorporated as explanatory variable, which could rule out the variation on students' overall academic efforts and performance in the statistical analyses to follow.

Of 53 registered students at the outset of the semester (Spring 2006), 37 completed the course and responded to both surveys. The statistics of students' background information collected from the preclass survey are summarized in Table 2, including demographics, academic background, learning style, computer proficiency, and prior knowledge and skills. Among the 37 valid subjects, most (36 out of 37) were engineering students. Students are approximately equally distributed among three grades: sophomore, junior, and senior, with an average age of just under 21. In terms of learning style, students are inclined to learn through watching and doing, although the inclination is not very significant. Students are likely to embrace innovative learning styles, while their attitude toward actively searching for new information is neutral. In terms of professional background, only one student has a transportation-related background before the class and 3

students expressed a desire to pursue a career in transportation (most were undecided; structural engineering was the most common subfield). Thus, it is not surprising that most of the subjects assess their transportation-related knowledge and skills as poor. On the other hand, students overwhelmingly rate their computer knowledge as proficient and they actually report spending on an average of $18 \mathrm{~h}$ a week before the screen. All of them have access to the Internet at home. This information favors the use of online simulation.

Results from the postclass survey are summarized in Table 3. As can be seen, students generally agree that ADAM improves their understanding of travel demand modeling, transportation planning, and transportation projects, which implies that ADAM is effective as a learning tool. As indicated in Table 4, ADAM significantly increases students' perceived skills of identifying relationships between components in the transportation system, forming opinions and judgments.

Students rate ADAM as an easy, clear, and pleasant tool for learning, which is consistent with their positive overall evaluation of this simulator. While they generally agree that ADAM enhances their learning through practical experience and interactive teaching, students are neutral about whether ADAM provides the opportunity for them to practice what they learned from lectures. This is partly due to the fact that, although detailed documentation was provided, the simulator itself still hides a great deal of model detail and is significantly different from traditional fourstep equations learned in lectures and the textbook [in this semester Banks (2002)]. In terms of the quality of project design and supporting materials, students are generally satisfied.

Does ADAM outperform conventional paper and pencil teaching strategies? Ideally, a between-subjects experiment should be conducted where two groups of students are randomly assigned to classrooms using the two different teaching strategies. Then, performance may be directly compared. However, it is problematic to use control groups in real classrooms during the same semester. There are too few students in a semester to divide into two different classrooms. Furthermore, the different classroom treatments may be perceived as unfair by students who have real grades riding on their performance. Instead, this analysis compares survey data collected from two different semesters. A later survey conducted in the Fall of 2006 focused on the same content but instead used the traditional pencil and paper teaching strategies, rather than making use of the simulator ADAM. The background information from the later survey of the 38 respondents is also summarized in Table 2. These students share similar demographic background and learning styles with their peers from the Spring semester. However, students in the Fall semester rated themselves higher regarding their prior knowledge and skills in transportation planning before taking the class. To control inconsistencies in self-evaluation, we compared the relative rated improvements of each individual, instead of the absolute value ratings of skills. Table 4 compares the self-reported level of skill in transportation planning before and after the class for both the control group and the treatment group. Unsurprisingly, students in both groups feel that they have benefited from the class. However, the magnitude of improvement in all three skill areas is larger for students who learn through ADAM. This improvement is only statistically significant regarding the ability to identify relationships among components of transportation systems. A larger sample may be required to draw more convincing conclusions. 
Table 2. Background of Students

\begin{tabular}{|c|c|c|c|c|c|}
\hline \multirow[b]{2}{*}{ Students' background } & & \multicolumn{2}{|c|}{ ADAM based } & \multicolumn{2}{|c|}{ Conventional } \\
\hline & & Counts/mean & SD & Counts/mean & SD \\
\hline \multirow{3}{*}{ Demographic } & Observations & 37 & & 38 & \\
\hline & Age & 20.83 & 2.42 & 22 & 3.93 \\
\hline & Gender & & & & \\
\hline \multirow{5}{*}{ Academic } & Female & 7 & & 7 & \\
\hline & Male & 30 & & 31 & \\
\hline & Education level & & & & \\
\hline & Senior & 11 & & 7 & \\
\hline & Junior & 14 & & 13 & \\
\hline \multirow{4}{*}{ Professional } & Sophomore & 12 & & 13 & \\
\hline & Previous experience & & & & \\
\hline & Yes & 1 & & 4 & \\
\hline & No & 36 & & 34 & \\
\hline \multirow{7}{*}{ Technical capacity } & Consider transportation career & & & & \\
\hline & Yes & 3 & & 5 & \\
\hline & No & 7 & & 18 & \\
\hline & NA & 27 & & 15 & \\
\hline & Own computers at home? & $100 \%$ & & $97.3 \%$ & \\
\hline & Weekly computer usage (h) & 18.48 & 9.92 & 15.01 & 10.46 \\
\hline & Computer proficiency $(1=$ very proficient, $5=$ none $)$ & 1.96 & 0.60 & 2.21 & 0.62 \\
\hline \multirow[t]{12}{*}{ Learning style } & Kolb's learning style (count) & & & & \\
\hline & Feeling & 10 & & 8 & \\
\hline & Watching & 14 & & 21 & \\
\hline & Thinking & 13 & & 12 & \\
\hline & Doing & 18 & & 33 & \\
\hline & $\begin{array}{l}\text { Felder-Silverman } \\
\quad \text { (scale 1-5) }\end{array}$ & & & & \\
\hline & Sensing versus intuitive & 2.86 & 0.85 & 2.68 & 1.86 \\
\hline & Visual versus verbal & 2.45 & 0.90 & 2.26 & 1.84 \\
\hline & Active versus reflective & 2.48 & 0.96 & 2.10 & 1.78 \\
\hline & Sequential versus global & 2.64 & 0.95 & 2.57 & 1.00 \\
\hline & Motivated by innovative teaching strategies & 2.24 & 0.72 & 2.18 & 0.73 \\
\hline & Searching versus accepting & 3.08 & 0.95 & 3.23 & 1.12 \\
\hline \multirow{3}{*}{$\begin{array}{l}\text { Prior understanding of the subject } \\
(1=\text { poor, } 5=\text { very good })\end{array}$} & Travel demand modeling & 1.45 & 0.50 & 1.68 & 0.70 \\
\hline & Transportation planning & 1.48 & 0.50 & 2.00 & 0.96 \\
\hline & Transportation project evaluation & 1.56 & 0.65 & 1.87 & 0.84 \\
\hline \multirow{3}{*}{$\begin{array}{l}\text { Prior skill assessment } \\
(1=\text { poor, } 5=\text { very good })\end{array}$} & Identify relationship among components & 2.24 & 0.76 & 2.97 & 0.94 \\
\hline & Form opinions & 2.75 & 0.86 & 3.34 & 1.04 \\
\hline & Comparison and judgment & 2.43 & 0.76 & 3.00 & 1.01 \\
\hline
\end{tabular}

\section{Who Benefits More?}

Knowing the characteristics of students who are more likely to capture the benefits of simulation-based teaching strategy has valuable implications for future research and educational practice to apply online simulation in classroom setting. Therefore, linear regressions are carried out with regard to students' learning performance indicators, including scores on the quiz I, self-reported improvements on knowledge and improvements on self-perceived skills. A correlation analysis conducted beforehand indicates that improvements on three kinds of knowledge and three kinds of skills listed in Table 3 are positively correlated. Thus, only one out of three indicators of a kind is drawn for statistical analysis. As shown in Table 5, explanatory variables contain information obtained in the preclass survey and final scores, some of which are dropped if they are not significant in preliminary regressions. A higher r-squared implies more significant relationship among dependent and independent variables. As shown by the regression results, students preferring visual learning are more likely to gain from simulation-based teaching according to the negative coefficient and statistical significance. Similarly, active learners (learning through doing) are more likely to improve their skill of evaluating alternative projects and making judgments. Students who are more enthusiastic about innovative teaching strategies are likely to form a better understanding of transportation planning after learning through simulation; however, their improvement in skills is not as significant as those favoring traditional classroom teaching. This difference implies that while the former group is more comfortable with simulation-based learning, the latter more likely benefits from innovative teaching strategies. Final scores are highly correlated with students' performance in quiz I. Interestingly, scores of the ability to evaluate transportation project reported before taking the class is negatively correlated with their understanding of travel demand modeling after 
Table 3. Learning Outcome Assessment

\begin{tabular}{|c|c|c|c|}
\hline Learning outcomes & & Mean & SD \\
\hline & Observations & 37 & \\
\hline \multicolumn{4}{|c|}{ Perceived improvements on subject understanding ( $1=$ poor, $5=$ very good $)$} \\
\hline & Travel demand modeling & 3.59 & 0.83 \\
\hline & Transportation planning & 3.38 & 0.82 \\
\hline & Transportation project evaluation & 3.28 & 0.96 \\
\hline
\end{tabular}

Perceived skills after projects $(1=$ poor, $5=$ very good $)$

$\begin{array}{ccc}\text { Identify relationship among components } & 3.54 & 0.73 \\ \text { Form options } & 3.43 & 0.76 \\ \text { Comparison and judgment } & 3.48 & 0.83\end{array}$

Efficacy assessment of ADAM as a learning tool

Interface $(0=$ poor, $9=$ very good $)$

System design $(0=$ poor, $9=$ very good $)$

Efficacy of enhancing learning through $(1=$ disagree, $5=$ agree $)$

Overall satisfaction $(1=$ low, $5=$ high $)$

\begin{tabular}{ccc} 
Reading on screen & 6.32 & 2.37 \\
Information organization & 5.46 & 2.04 \\
Indication of system progress & 5.22 & 2.05 \\
Overall satisfaction & 5.49 & 2.02 \\
Easy to access & $100 \%$ & \\
Speed satisfaction & 6.05 & 2.07 \\
Practice of skills & 2.94 & 0.97 \\
Practical experience & 3.21 & 0.85 \\
Interactive approach & 3.27 & 0.99 \\
Motivating teaching strategies & 3.00 & 0.99 \\
Easy to learn & 3.67 & 1.05 \\
Quality as a learning tool & 3.08 & 0.98 \\
Learning experience with ADAM & 3.18 & 0.99 \\
Overall satisfaction & 3.08 & 0.86 \\
& & \\
& & \\
Overall satisfaction & 3.11 & 1.07 \\
Quality of design & 3.29 & 0.84 \\
Time taken to accomplish work & 2.51 & 0.69 \\
Supporting information proficiency & 3.56 & 1.04 \\
Information clarity & 3.32 & 0.91 \\
\hline
\end{tabular}

the project. The most plausible explanation for this result is that students who have little knowledge of the transportation planning experience before they take the class tend to believe that their knowledge is significantly improved after they complete the class. As a result, they tend to give more aggressive ratings of their improved understanding of travel-demand modeling. Alternatively, students that already feel comfortable with the material tend to understate any improvements in their understanding of the subject.

As shown in Table 5, the variables of demographic, academic and professional background, and computer proficiency are not statistically significant. This could be explained by the fact that the majority of the class has little prior experience in this field, thus they are all novices despite the differences in grade, age, and gender. The survey reports that students believe the simulator is simple and easy to learn, which diminishes the importance of computer proficiency in student performance. This is consistent with our design philosophy too.

\section{Conclusions}

Findings from this research are twofold: first, ADAM's performance in the classroom is consistent with its design philosophy. It

Table 4. Perceived Improvement in Skills after Simulation-Based Project

\begin{tabular}{|c|c|c|c|c|c|c|c|c|c|c|}
\hline \multirow[b]{3}{*}{ Skills } & \multicolumn{10}{|c|}{ Mean score of self-reported ability $(1=$ poor; $5=$ very good $)$} \\
\hline & \multicolumn{4}{|c|}{ ADAM-based class } & \multicolumn{4}{|c|}{ Conventional class } & \multicolumn{2}{|c|}{ ADAM versus conventional } \\
\hline & Before & After & Increase & $t$ & Before & After & Increase & $t$ & Difference & $t$ \\
\hline Identify relationship among components & 2.24 & 3.54 & 1.3 & $14.3^{\mathrm{a}}$ & 2.97 & 3.66 & 0.69 & $3.3^{\mathrm{a}}$ & 0.6 & $2.38^{\mathrm{a}}$ \\
\hline Form options & 2.76 & 3.43 & 0.67 & $7.95^{\mathrm{a}}$ & 3.34 & 3.86 & 0.52 & $2.6^{\mathrm{a}}$ & 0.15 & 0.72 \\
\hline Comparison and judgment & 2.43 & 3.49 & 1.06 & $11.9^{\mathrm{a}}$ & 3 & 3.86 & 0.86 & $4.2^{\mathrm{a}}$ & 0.2 & 0.64 \\
\hline
\end{tabular}

${ }^{\mathrm{a}}$ Significant at $99 \%$ confidence interval. 
Table 5. Students' Performance and Self-Evaluation versus Students' Characteristics

\begin{tabular}{|c|c|c|c|c|c|c|}
\hline \multirow[b]{3}{*}{ Explanatory variables } & \multirow{2}{*}{\multicolumn{2}{|c|}{$\frac{\text { Students' characteristics versus }}{\text { Scores in quiz I }}$}} & \multicolumn{4}{|c|}{ Students' characteristics versus perceived improvement of } \\
\hline & & & \multicolumn{2}{|c|}{ Understanding on transportation planning } & \multicolumn{2}{|c|}{ Skills of judgment } \\
\hline & Coefficient & $t$ & Coefficient & $t$ & Coefficient & $t$ \\
\hline Junior $[1,0]$ & -6.97 & $-1.68^{\mathrm{a}}$ & 0.70 & $2.27^{\mathrm{b}}$ & 0.53 & 1.33 \\
\hline Senior $[1,0]$ & & & & & 0.48 & 1.02 \\
\hline Sensing versus intuitive ${ }^{c}$ & & & 0.21 & 1.11 & -0.21 & -0.91 \\
\hline Visual versus verbal $^{c}$ & -4.83 & $-1.95^{\mathrm{a}}$ & -0.39 & $-2.22^{\mathrm{b}}$ & 0.24 & 1.16 \\
\hline Active versus reflective $^{c}$ & 3.28 & 1.23 & 0.26 & $1.69^{\mathrm{a}}$ & -0.43 & $-2.17^{\mathrm{b}}$ \\
\hline Sequential versus global $^{\mathrm{c}}$ & 2.71 & 1.25 & -0.14 & -0.95 & & \\
\hline Motivated by innovative teaching strategies ${ }^{c}$ & -1.47 & -0.51 & -0.50 & $-2.42^{\mathrm{b}}$ & 0.56 & $2.48^{\mathrm{b}}$ \\
\hline Transportation planning $^{\mathrm{d}}$ & -7.88 & $-1.75^{\mathrm{a}}$ & -0.21 & -0.67 & 0.47 & 1.34 \\
\hline Transportation project evaluation $^{\mathrm{d}}$ & & & 0.31 & 1.22 & & \\
\hline Identify relationship among components ${ }^{\mathrm{d}}$ & & & 0.15 & 0.73 & -0.31 & -1.36 \\
\hline Form options ${ }^{\mathrm{d}}$ & 3.05 & 1.22 & 0.21 & 0.92 & 0.56 & $2.48^{\mathrm{b}}$ \\
\hline Comparison and judgment $^{\mathrm{d}}$ & & & -0.67 & $-2.01^{\mathrm{b}}$ & & \\
\hline Final scores (100 based) & 1.17 & $4.29^{\mathrm{e}}$ & & & & \\
\hline \multirow[t]{2}{*}{ Constant } & -34.0 & -1.24 & 5.39 & 3.84 & -1.04 & -0.72 \\
\hline & \multicolumn{2}{|c|}{$R^{2}=0.76$} & \multicolumn{2}{|c|}{$R^{2}=0.67$} & \multicolumn{2}{|c|}{$R^{2}=0.66$} \\
\hline
\end{tabular}

${ }^{a}$ Significant at $90 \%$ confidence interval.

${ }^{\mathrm{b}}$ Significant at $95 \%$ confidence interval.

${ }^{\mathrm{c}}$ Felder and Silverman's index ranging from 1 to 5 .

${ }^{\mathrm{d}} 1=$ poor in knowledge or skills before the class; $5=$ very good in knowledge or skills before the class.

${ }^{\mathrm{e}}$ Significant at $99 \%$ confidence interval.

is a simple, flexible, engaging, and enlightening teaching tool. Results from our surveys reveal that a curriculum centered on problem-solving and enhanced by simulation tools can effectively improve classroom outcomes. Students improved their understanding of the transportation planning evaluation process and were more likely to use better judgment regarding analysis of transportation projects.

Second, the study finds that not all students benefit equally. Learning style plays an important role in determining the gains from a simulation-based teaching strategy. Visual and active learners captured more benefits from this strategy, while those who preferred sensing and sequential learning did not demonstrate higher performance. We speculate that this finding may relate to the holistic nature of integrated simulation models, which contrasts with the reductionism of four-step models. The methods developed in this paper are designed to enhance rather than replace traditional teaching styles so as to incorporate all learning styles.

Future work includes running this study with a larger sample size and a comparison study of a treatment group and better experiment design so that more confounding factors can be controlled.

\section{Acknowledgments}

This material is based upon work supported by the National Science Foundation under Grant No. 0717504. STREET: Simulating Transportation for Realistic Engineering and Education and the University of Minnesota Digital Media Center.

\section{References}

Alavi, M., Yoo, Y., and Vogel, D. R. (1997). "Using information technology to add value to management education.” Acad. Manage J., 40(6),
$1310-1333$

Banks, J. H. (2002). Introduction to transportation engineering, 2nd Ed., McGraw-Hill, New York.

Billhardt, B. (2004). "The promise of on-line simulation." MediaTec Publishing, Inc., Chicago, 〈http://www.clomedia.com/content/templates/ clo_feature.asp?articleid=382 $($ July 18, 2006).

Bolay, K., and Helbing, D. (2006). Cellular automaton traffic simulators. 〈http://rcswww.urz.tu-dresden.de/ helbing/RoadApplet/〉 (July 18, 2006).

Carlson, L. E., and Sullivan, J. F. (1999). "Hands-on engineering: Learning by doing in the integrated teaching and learning program." Int. $J$. Eng. Educ., 15, 20-31.

Chen, W. and Levinson, D M.. (2006). "Effectiveness of learning transportation network growth through simulation." J. Profl. Issues Eng. Educ. Pract., 132(1), 29-41.

Chickering, A., and Gamson, Z. (1987). "Seven principles for good practice." AAHE Bulletin, 39, 3-7.

Felder, R. M., and Silverman, L. K. (1988). "Learning and teaching styles in engineering education." Eng. Educ., 78(7), 674-681.

Hadgraft, R. G. (1992). "Experiences of two problem-oriented courses in Civil Engineering." Eur. J. Eng. Educ., 17(4), 345-353.

Handy, S., Weston, L., Song, J., Maria, K., and Lane, D. (2002). "Education of transportation planning professionals." Transp. Res. Rec., 1812, 151-160.

ITE Technical Council Committee 2-32. (1990). "Attracting students to a professional career in transportation engineering." ITE J., 60(1), 4248.

Kolb, D. A. (1984). Experiential learning: Experience as the source of learning and development, Prentice-Hall, N.J..

Lipinski, M. E., and Wilson, E. M. (1992). "Undergraduate transportation education: Who is responsible?" ITE J., 63(8), 29-32.

Los Alamos National Laboratory. (1998). "Cellular automation traffic microsimulation," Paper Prepared for the U. S. Dept. of Energy, Univ. of California, 〈http://public.lanl.gov/bwb/Java/lanl/bwbush/ transims/simulate.html $\rangle$ (Jul. 18, 2006).

Mason, J. M. (2003). "Transportation education and workforce development.” ITE J., 73(9), 22-25. 
Mills, J. E., and Treagust, D. F. (2003). "Engineering education-Is problem-based or project-based learning the answer?" Aust. J. Eng. Educ., 3, 2-16〈http://www.aaee.com.au/journal/2003/mills_treagust 03.pdf $\rangle$.

Parthasarathi, P., Levinson, D., and Karamalaputi, R. (2003). "Induced demand: A microscopic perspective." Urban Stud., 40(7), 1335-1351.

Rafaeli, S., Raban, R. D., Ravid, G., and Noya, A. (2003). "On-line simulations in management education about information and its use." Research in management education and development, Information Age Publishing, Inc., Charlotte, N.C., 53-80.
Sheffi, Y. (1985). Urban transportation networks: Equilibrium analysis with mathematical programming methods, Prentice-Hall, New Jersey.

Stoffa, V., and Slovakia, N. (2004). "Modelling and simulation as a recognizing method in education." Educ. Media Int., 41(1), 51-58.

Treiber, M. (2005). "Microsimulation of road traffic." Dresden Univ. of Technology, Dresden, Germany, 〈http://vwisb7.vkw.tu-dresden.de/ $\sim$ treiber/MicroApplet/> (July 18, 2006).

Zhang, L., and Levinson, D. (2004). "Agent-Based approach to travel demand modeling: An exploratory analysis." Transp. Res. Rec., 1898, $28-36$. 